\title{
POLYSULFONE MEMBRANE WITH ZEOLITE FILLER FOR CO2/CH4 GAS SEPARATION: A REVIEW
}

\section{${ }^{1}$ Indri Susanti}

1Department of Science Education, Faculty of Teacher Training and Education, Lamongan Islamic University. Jl. Veteran No.53A Lamongan, Indonesia

Email: indri_susanti@unisla.ac.id; indrisusanti077@gmail.com

\section{Article History}

Received: 11 January

Revised: 25 February

Published: March 2019

\begin{abstract}
Membrane technology for gas separation applications are limited by a "trade-off" curve between permeability and selectivity. It show that permeability is high, selectivity obtained is low. This problem can be solved by preparation of MixedMatrix Membrane (MMMs) which can increase the value of permeability and selectivity. The MMMs with polysulfone polymers and zeolite fillers is more corresponding for gas separation. Addition of zeolite filler to polysulfone polymer in MMMs can improve the CO2 separation performance. In this review, mechanism of gas separation in MMMs was carried out in the application of $\mathrm{CO} 2 / \mathrm{CH} 4$ gas separation. In addition, the effect of addition, size and pore of zeolite filler in MMMs for binary gas separation were also discussed in this review.
\end{abstract}

Keywords: Mixed-Matrix Membrane (MMMs); $\mathrm{CO}_{2} / \mathrm{CH}_{4}$ Gas Separation; Polysulfone Polymer; Zeolite; Review.

How to cite: Susanti, Indri. (2019). POLYSULFONE MEMBRANE WITH ZEOLITE FILLER FOR CO2/CH4 GAS SEPARATION: A REVIEW. Science Education and Application Journal (SEAJ). Vol. 1 No.1: 10-16.

\section{INTRODUCTION (12pt)}

Fossil fuels combustion produces components and contaminants such as $\mathrm{CO}_{2}, \mathrm{O}_{2}, \mathrm{~N}_{2}$, $\mathrm{H}_{2} \mathrm{O}$, and $\mathrm{H}_{2} \mathrm{~S}$. Gas separation process should to be carried out for various applications later. The gas separation technology has been used is absorption technique using solvents such as polycarbonate and tributyl phosphate. However, the use of solvents in the gas separation process results contaminants which not environmentaly friendly and require high costs ${ }^{[8]}$.

In addition, the potential technology for gas separation and interesting to study is membrane technology. Membrane technology was applied to gas separation process until molecular level. Membrane technology has high efficiency and stability, more simple process, environmentally friendly, and low cost than other conventional processes ${ }^{[9]}$. Membranes are categorized into four types based on membrane material, that are: polymer membrane, inorganic membrane, liquid membrane, and mixed-matrix membrane (MMMs) ${ }^{[11]}$. However, the polymer membrane application is limited by performance of "Robeson trade-off line" curve between gas permeability and selectivity. The maximum performance of polymer membrane in gas separation at the "upper bound" which shows high selectivity and low permeability ${ }^{[11]}$. Inorganic membrane has high selectivity and thermal stability, but it has low permeability and sensitivity ${ }^{[11]}$. The efforts to develop membrane applications can be done with increasing the value of gas permeability and selectivity throught MMMs until reaches Robeson "upper bound".

Mixed-matrix membranes (MMMs) is a membrane consisting of a polymer and filler which can be composed by porous or non-porous inorganic material ${ }^{[9]}$. Some of the polymers has been used in MMMs are cellulose acetate, polymid [8], Polyacetylene, poly- 
dimethylsiloxane, poly-ethylsulfone ${ }^{[2]}$, Polysulfone ${ }^{[15]}$, and PVDF ${ }^{[19]}$. Polysulfone is a glass polymer that has adhesion between polymer-fillers. Polysulfone is better for MMMs preparation than elastic polymer ${ }^{[9]}$. In addition, polysulfone has good mechanical strength and thermal resistance ${ }^{[15]}$.

The first porous material has been used as filler in MMMs is zeolite ${ }^{[9]}$. Zeolite is a aluminosilicate crystals which have a cage-like pore shape or framework with molecular size $0,5-1,2 \mathrm{~nm}[3,13]$. Some zeolite type has been used as a filler in MMMs are zeolite-A ${ }^{[9]}$, zeolite-X ${ }^{[14]}$, Zeolite-Y ${ }^{[12]}$, zeolite-T ${ }^{[15]}, \mathrm{ZSM} 5^{[5]}$, and ZIF-8 ${ }^{[2]}$. In this article, a review was made of gas separation through mixed-matrixs membrane (MMMs) with polysulfone as polymer and zeolite as filler. Furthermore, this article also discuss about modification between polymer and zeolite, like the effect of adding zeolite and zeolite pore size in MMMs to $\mathrm{CO}_{2} / \mathrm{CH}_{4}$ gas separation.

\section{MIXED-MATRIX MEMBRANE (MMMS)}

MMMs is heterogeneous membrane consisting of inorganic filler which is affixed to a polymer matrix ${ }^{[7] . ~ T h e ~ s c h e m a t i c ~ o f ~ M M M s ~ w i t h ~ f a l t ~ m o d u l e s ~ i s ~ s h o w n ~ i n ~ f i g u r e ~} 1$. The inorganic filler in MMMs aims to form a special permeation path by increasing selective permeability. Molecular sieving properties of inorganic filler added to the polymer matrix results increasing gas permeability on MMMs. Adapun preparation process of polymer matrix membrane with inorganic filler is efficient ${ }^{[7]}$.

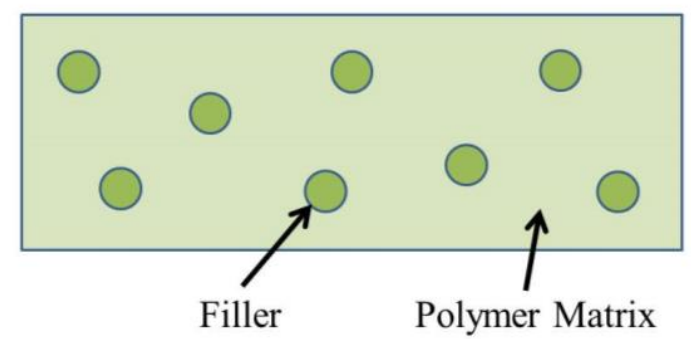

Figure 1. The schematic of MMMs with falt modules

MMMs with asymmetric hollow fiber modules have more effective membrane structure than flat modules. Hollow fiber membrane has a larger area per volume than flat module, good flexibility and simple preparation in module fabrication. Hollow fiber membrane has two layers that are widely applied due to some advantages, such as low material prices, easy synthesis process and better membrane performance than flat membrane ${ }^{[2]}$. The schematic of MMMs with hollow fiber modules is shown in figure 2 .

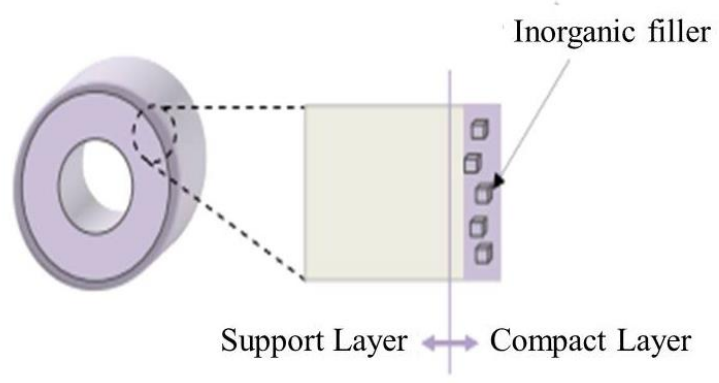

Figure 2. The schematic of MMMs with hollow fiber modules.

\section{Selection of Polymer and Filler in Mixed-Matrix Membranes (MMMs) Preparation for Gas Separation}


Selection of polymer and zeolite material is the important thing in Mixed-Matrix Membranes (MMMs) for gas separation. There are two types of polymer used in MMMs, that are glass polymer and rubbery polymer ${ }^{[2]}$. The rubbery polymer is more suitable for zeolite filler than glass polymer. However, it tends to push MMMs performance under "trade-off upperbond" curve ${ }^{[11]}$.

Some Polymers have been done in MMMs preparation are cellulose acetate, polymid [8], Polysulfone ${ }^{[15]}$, Polyacetylene, poly-ethylsulfone, poly-dimethylsiloxane ${ }^{[2],}$ and PVDF ${ }^{[19] .}$ Polysulfone is a glass polymer and hydrophobic that has adhesion between polymer-fillers. Polysulfone is better for MMMs preparation than elastic polymer ${ }^{[9] .}$ In addition, polysulfone has good mechanical strength and thermal resistance ${ }^{[15] .}$ The molecular sieving is important thing in the MMMs preparations for binary gas separation applications. The molecular sieving must be of the right size and has ability to distinguish gas molecules to be separated. Zeolite with three-dimensional network has a good diffusion path and it is corresponding for gas separation applications ${ }^{[2]}$. Zeoilte is the first porous material as a filler in the MMMs preparations [9]. Zeolite is an aluminosilicate crystal which have a cage-like pore shape or framework with molecular size $0,5-1,2 \mathrm{~nm}[3,13]$. Some zeolite type has been done as a filler in the MMMs are zeolite-A ${ }^{[9]}$, zeolite- $\mathrm{X}^{[14]}$, zeolite-Y ${ }^{[12]}$, zeolite-T ${ }^{[15]}$, ZSM-5 ${ }^{[5]}$, and ZIF-8 [2].

\section{MMMs Applications for Gas Separation}

Natural gas consumption has increased from year to year, i.e. 26,593 bcf (billion cubic feet) in 2014; 27,306 bcf in 2015, and 27,491 bcf in 2016 [17]. The composition of natural gas includes $\mathrm{CH}_{4}$ gas as the main component of natural gas, $\mathrm{CO}_{2}, \mathrm{H}_{2} \mathrm{~S}, \mathrm{H}_{2} \mathrm{O}, \mathrm{N}_{2}$, and hydrocarbon compounds such as ethane $\left(\mathrm{C}_{2} \mathrm{H}_{6}\right)$, propane $(\mathrm{C} 3 \mathrm{H} 8)$, and butane $\left(\mathrm{C}_{4} \mathrm{H}_{10}\right)$ [1]. The composition of natural gas with its concentration shown in Table 1 . The presence of several components of natural gas causes the gas separation is needed, then used to various applications.

Table 1. The composition of natural gas ${ }^{[1]}$

\begin{tabular}{cc}
\hline $\begin{array}{c}\text { Natural Gas } \\
\text { Content }\end{array}$ & $\begin{array}{c}\text { Consentration } \\
\text { (Mole.\%) }\end{array}$ \\
\hline $\mathrm{CH}_{4}$ & $29.98-90.12$ \\
$\mathrm{C}_{2} \mathrm{H}_{6}$ & $0.55-14.22$ \\
$\mathrm{C}_{3} \mathrm{H}_{8}$ & $0.23-12.54$ \\
$\mathrm{C}_{4} \mathrm{H}_{10}$ & $0.14-8.12$ \\
$\mathrm{C}_{5} \mathrm{H}_{12}$ & $0.037-3.0$ \\
$\mathrm{CO}_{2}$ & $0.06-42.66$ \\
$\mathrm{He}$ & $0.0-1.8$ \\
$\mathrm{~N}_{2}$ & $0.21-26.10$ \\
$\mathrm{H}_{2} \mathrm{~S}$ & $0.0-3.3$ \\
\hline
\end{tabular}

Based on the Table 1., $\mathrm{CH}_{4}$ gas has the greatest consentration in natural gas. Then the greatest consentration after $\mathrm{CH}_{4}$ gas is $\mathrm{CO}_{2}$. Therefore, the $\mathrm{CO}_{2} / \mathrm{CH}_{4}$ gas separation is required then used for other applications. In the last 10 years, a number of membrane materials have been synthesized using polymers such as polymid ${ }^{[8]}$, intrinsic microporosity polymer (PIMs) ${ }^{[16]}$, TR (thermal re-arranged) polymer ${ }^{[10]}$, and applied on a laboratory scale for $\mathrm{CO}_{2}$ gas separation from $\mathrm{CH}_{4}$. 


\section{Mechanism for Binary Gas Separation in the MMMs with Polysulfone Polymer and Zeolite Filler}

The mechanism of molecules transport in zeolite membrane begins with adsorption process of gas molecules on the surface of zeolite pore, then diffusion process around the surface of zeolite pore, and finally the desorption process to produce permeate [11]. Permeate is gas molecule has been separated from gas mixture in zeolite membrane (MMMs).

Tabel 2. Physical Properties of $\mathrm{CO}_{2}, \mathrm{CH}_{4}, \mathrm{~N}_{2}, \mathrm{O}_{2}$, and $\mathrm{H}_{2}$ gas [2,23].

\begin{tabular}{lccccc}
\hline \multicolumn{1}{c}{ Physical Properties } & $\mathbf{C O}_{2}$ & $\mathbf{C H}_{\mathbf{4}}$ & $\mathbf{N}_{\mathbf{2}}$ & $\mathbf{O}_{\mathbf{2}}$ & $\mathbf{H}_{\mathbf{2}}$ \\
& & & & & \\
\hline Molecular Weight $(\mathrm{g} / \mathrm{mole})$ & 44.01 & 16.04 & 28.01 & 31.99 & 2.02 \\
Kinetic Diameter $(\AA)$ & 3.3 & 3.8 & 3.64 & 3.46 & 2.89 \\
Critical Temperature $\left({ }^{\circ} \mathrm{C}\right)$ & 31 & -82.1 & -147.1 & -118.6 & -240.2 \\
Critical Pressure $(\mathrm{atm})$ & 72.9 & 45.8 & 33.5 & 49.77 & 12.8 \\
Critical Density $(\mathrm{g} / \mathrm{mL})$ & 0.468 & 0.162 & 0.311 & 0.436 & 0.031 \\
\hline
\end{tabular}

Gas adsorption process on the zeolite is a physisorption. The adsorption is exothermic and reversible ${ }^{[4]}$. Molecules are adsorbed into the zeolite pore due to the intermolecular interactions between adsorbent and adsorbaate ${ }^{[2]}$. In this case the adsorbent is zeolite membrane (MMMs) and the adsorbate is $\mathrm{CO}_{2}$ gas. Adsorption of $\mathrm{CO}_{2}$ gas on the zeolite is stronger than other gases such as $\mathrm{H}_{2}, \mathrm{CH}_{4}$ dan $\mathrm{N}_{2}$. It causes of the dipole and quadrupole moments. The $\mathrm{CO}_{2}$ molecule has dipole and quadrupole moments are higher than other gases ${ }^{[11]}$. The physical properties of several gas molecules are listed in Table 2 .

Table 3. Structure Properties of Zeolites

\begin{tabular}{ccccc}
\hline Zeolite & Zeolite Type & $\begin{array}{c}\text { Dimension } \\
\text { Structure }\end{array}$ & Pore Size (̊̊) & Reference \\
\hline 4A & LTA & 3D & 3.8 & {$[2]$} \\
5A & LTA & 3D & 4.3 & {$[2]$} \\
X & Faujasit & 3D & 7.4 & {$[21]$} \\
Y & Faujasite & 3D & 7.4 & {$[21]$} \\
L & LTL & 2D & 7.1 & {$[2]$} \\
ZSM-5 & MFI & 2D & 5.6 & {$[21]$} \\
ZSM-2 & Faujasite & 3D & 5.7 & {$[27]$} \\
SAPO-34 & CHA & 3D & 3.8 & {$[2]$} \\
\hline
\end{tabular}

Figure 3. The Schematic of Binary Gas Separation

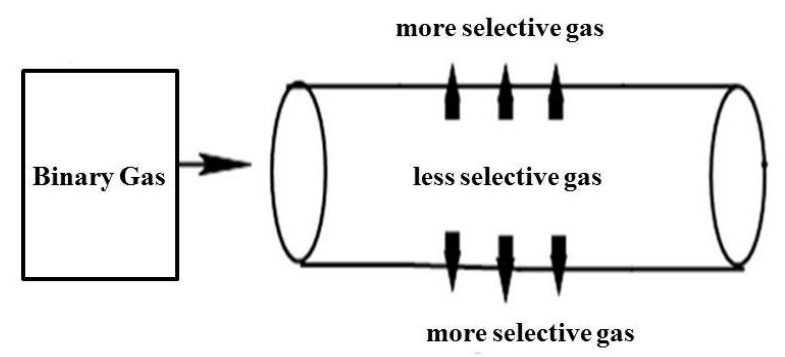

Figure 3 illustrate the process of binary gas separation. On the binary gas separtion, selective gas in the MMMs will be diffused towards the outer layer and comes out as the permeate. Whereas, the less selective gas will be in the inner layer of membrane as a retentate. 


\section{RESULT AND DISCUSSION}

\section{A. The Effect of Addition Zeolite Filler in MMMs for Gas Separation}

The performance of MMMs is influenced by the number of zeolite filler added to polymer matrix. The increasing in the number of zeolite filler on polymer matrix can increase the value of permeability. The increasing the number of zeolites on polymer matrix cause the formation of an interface cavity that arises due to reduced adhesion between polymer and zeolite particle [5]. As shown in Table 4, addition of ZSM-5 filler with different amounts on polysulfone membranes showed different permeability value. Addition of ZSM-5 filler for 10\%wt and 20\%wt produces the permeability value of 2.0047 dan 2.2074 Barrer, respectively [5]. Nevertheless, in some other MMMs, the addition of zeolite filler decreases permeability value. [2].

\section{B. The Effect of Zeolite Particle Size in MMMs for Gas Separation}

The enhancement of zeolite particle size increase permeability value. The permeability value of Silicate-PDMS MMMs increases with increasing particle size of crystal silicate. The small zeolite particle size causes permeation process is difficult due to the number area of zeolite-polymer interface increased. It causes the mass transfer of molecule gas disturbed. However, the selectivity of MMMs in gas separation not affected by transformation of zeolite particle size [2].

\section{The Effect of Zeolite Pore Size in MMMs for Gas Separation}

Zeolite pore size also affects MMMs performance for gas separation. The larger zeolite pore size increases the MMMs performance in gas separation through the increasing permeablity value. The large zeolite pore size reduces the occurrence of pore blockages in MMMs. In addition, gas molecules transport more easily pass through the larger zeolite pore and it causes the enhancement of permeability value [2]. However, the very large of zeolite pore size reduces selectivity value due to other gases also enter the zeolite pore. Therefore, selection of zeolite filler must be adsjusted between zeolite pore size and kinetic diameter of gas molecules to be separated.

Based on the Table 4., polysulfone membrane with zeolite-13X as a filler produces the larger permeability value than zeolite-A filler. It's corresponded with zeolites pore size are listed in Table 2 which show that zeolite-X pore size is larger than zeolite-A.

Table 4. Polysulfone Membrane with Zeolitee Filler

\begin{tabular}{cccccccc}
\hline Polymer / Filler & $\mathbf{a}$ & $\mathbf{b}$ & $\mathbf{c}$ & $\mathbf{d}$ & $\mathbf{e}$ & $\mathbf{f}$ & Reference \\
\hline PSf/Zeolite-T & 3 & 2 & 25 & 78.90 & 3.37 & - & {$[15]$} \\
PSf/ Zeolite SAPO-34 & 10 & 3.48 & 25 & 314.02 & 28.2 & - & {$[8]$} \\
PSf/ZSM-5 & 10 & $2-5$ & & - & 4.1351 & 2.0047 & \\
PSf/Zeolite-13X & 20 & $2-5$ & 35 & - & 2.3369 & 2.2074 & {$[5]$} \\
PSf -Ac/ Zeolite-3A & 50 & 10 & 25 & - & - & 4.85 & {$[9]$} \\
PSf/Zeolite-4A & - & 2 atm & 25 & $176-3720$ & 1.6 & - & {$[2]$} \\
PSf/ZIF-8 & 16 & 1 & - & - & 19.10 & 12.10 & {$[2]$} \\
PSf / silica (rice husk) & 40 & - & - & - & 33.31 & 8.46 & {$[22]$} \\
Pure polysulfone & - & - & - & - & 2.63 & 12.33 & {$[15]$} \\
\hline
\end{tabular}


Explanation: $\mathrm{a}=$ Filler $(\% \mathrm{wt}$. $) ; \mathrm{b}=$ Pressure (bar); $\mathrm{c}=$ Temperature $\left({ }^{\circ} \mathrm{C}\right) ; \mathrm{d}=$ Permeation $(\mathrm{GPU}) ; \mathrm{e}=\mathrm{CO}_{2} / \mathrm{CH}_{4}$ Selectivity $; \mathrm{f}=$ Permeability (Barrer).

\section{CONCLUSION AND SUGGESTION}

Mixed-Matrix Membrane (MMMs) with zeolite filler corresponds to binary gas separation. MMMs with polysulfone polymer and zeolite filler increases the performance of gas separation due to the enhancement of permeability and selectivity value. Mixed-Matrix Membranes (MMMs) preparation with polysulfone polymer have been synthesized using zeolite-X filler. The further research in MMMs can be synthesized with zeolite-Y filler due to the zeolite-Y $(7,4 \AA)$ pore size similar with zeolite-X $(7,4 \AA)$. In addition, the pore size of zeolite-Y $(7,4 \AA)$ is larger than zeolite-A $(3,8 \AA)$ which can increase permeability value. It's due to the zeolite pore size enhancement can increase the value of permeability.

\section{ACKNOWLEDGEMENT}

Authors wish to thank to Universitas Islam Lamongan (UNISLA), East Java, Indonesia and the Ministry of Research, Technology and Higher Education of Indonesia for providing their facilities and helps for this article.

\section{REFERENCES}

[1] Adewole, J.K., Ahmad, A.L., Ismail, S., Leo, C.P., Greenh, Int. J., (2013). Gas Control. 17. hal. $46-65$.

[2] Bastani, D., Esmaeili, N., Asadollahi, M., (2013). "Polymeric mixed matrix membranes containing zeolites as a filler for gas separation applications: A review." Journal of Industrial and Enginering Chemistry 19. hal 375-393.

[3] Chester, A. W. dan Derouane, E. G., (2009), "Zeolite Characterization dan Catalysis", Springer, New York Cheung O., Bacsik Z., Liu Q., Mace A. dan Hedin N., (2013), "Adsorption for $\mathrm{CO}_{2}$ on highly selective zeolites NaKAdannano-NaKA", Applied Energy, 112, hal. 1326-1336.

[4] Dai, Z., Bai, L., Hval, K.N., Zhang, X., Zhang, S., Deng, L., (2016). J. Membr, Sci. China Chem. 497. hal.1-20.

[5] Dorosti, F., Omidkhah, M.R., Pedram, M.Z., Moghadam, F., (2011). Fabrication and characterization of polysulfone/ polymide-zeolite mixed matrix membrane for gas separation. Chemical Engineering Journal 171. hal 1469-1475.

[6] Gong, H., Lee, S.S., Bae, T.H., (2017). "Mixed-matrix membranes containing inorganically surface-modified 5A zeolite for enhanced $\mathrm{CO}_{2} / \mathrm{CH}_{4}$ separation." Microporous and Mesoporous Materials 237. hal 82-89.

[7] Ismail, A.F., Rahim, R.A., Rahman, W.A.W.A., (2008). Separation and Purification Technology. 63. 200.

[8] Junaidi, M.U.M., Leo, C.P., Ahmad, A.L., Kamal, S.N.M., Chew, T.L., (2014). "Carbon dioxide separation using asymmetric polysulfone mixed matrix membranes incorporated with SAPO-34 zeolite." Fuel Processing Technology 118. hal 125-132.

[9] Khan, A.L., Cano-Odena, A., Gutierrez, B., Minguillon, C., Vankelecom, Ivo F.J., (2010). "Hydrogen separation and purification using polysulfone acrylate-zeolite mixed matrix membranes." Journal of membrane Science 350. hal 340-346.

[10] Kim, S., Lee, Y.M., (2015), Prog. Polym. Sci. 43. hal. 1-32.

[11] Kosinov, N., Gascon, J., Kapteijn, F., Hensen, E.J.M., (2016). "Recent developments in zeolite membranes for gas separation." Journal of Membrane Science 499. hal 65-79. 
[12] Kusukabe, K., Kuroda, T., Murata, A., Morooka, S., (1997). "Formation of a Y-Type Zeolite Membrane on Porous $\alpha$-Alumina Tube for Gas Separation". Material and Interfaces Journal. 36. hal. 649-65.

[13] Langmi H. W., Walton A., Al-Mamouri M. M., Johnson S. R., Book D., Speight J. D., Edwards P. P., Gameson I., Danerson P. A. dan Harris I. R., (2003), "Hydrogen adsorption in zeolites A, X, Y dan RHO", Journal of Alloys dan Compounds, 356-357, hal. 710-715.

[14] Mahmoudi, A., Namdari, M., Zargar, V., Khanbabaei, G., Asghari, M., (2014). "Nano composite PEBAX membranes: Effect of zeolite $\mathrm{X}$ filler on $\mathrm{CO}_{2}$ permeation." International Journal of Nano Dimension 5(1). Hal 83-89.

[15] Mohamad, M. Bt., Fong, Y.Y., Shariff, A., (2016). " Gas separation of carbon dioxide from methane using polysulfone membrane incorporated with zeolite-T". Procedia Engineering 148. hal 621-629.

[16] McKeown, N.B., Budd, P.M., (2010). 1. hal. 63-68.

[17] NOAA, (2017). "National Oceanic and Atmosphere Administration". [online]. Tersedia di http://www.noaanews.noaa.gov/ [Diakses pada 7 September 2017].

[18] Rezakazemi M, Amooghin A.E., Rahmawati-Montazer M.M., Ismail A.F., Matsuura. State-of-the-art membrane based CO2separation usingmixed matrix membranes (MMMs): An overview on currentstatus and future directions. Progress in Polimer Science 39 (2014) $817-861$.

[19] Shen, Y., Lua, A.C., (2012). "Preparation and characterization of mixed matrix membranes based on PVDF and three inorganic filler (fumed nonporous silica, zeolite 4A and mesoporous MCM-41) for gas separation." Chemical Engineering Journal 192. hal 201-210.

[20] Vanherck, K., Koeckelberghs, G., Vankelecom, I.F.J., (2013). Prog. Polym. Sci. 38. (6). hal. 874-896.

[21] Weitkamp, J., 2000. Zeolites and Catalysis. Solid State Ionics, 131, hal. 175-188.

[22] Waheed, N., Mushtaq, A., Tabssum, S., Gilani, M.A., Ilyas, A., Ashraf, F., Jamal, Y., Bilad, M.R., Khan, A.U., Khan., A.L., (2016). "Mixed-Matrixs Membrane Base on Polysulfon and Rice husk Extracted Silica for $\mathrm{CO}_{2}$ Separation. Separation and Purification Technology 170. hal. 122-129.

[23] Shekhawat, D., Luebke, D.R., Pennline, H.W., (2003). “A review of carbon dioxide selective membranes, A Topical Report", National Energy Technology Laboratory United States Department of Energy. 